\title{
Effects of Economic Growth on Environmental Degradation in the Republic of Congo: The Case of $\mathrm{CO}_{2}$ Emissions
}

\author{
Geslin William Ondaye, Christelle Ines Leticia Ndombi Ondze, Espérance Hotale Imongui \\ Laboratory of Economic and Social Research and Studies, Faculty of Economic Sciences, Marien Ngouabi University, Brazzaville, \\ Republic of the Congo \\ Email: ondaye.william@yahoo.fr
}

How to cite this paper: Ondaye, G. W., Ondze, C. I. L. N., \& Imongui, E. H. (2021). Effects of Economic Growth on Environmental Degradation in the Republic of Congo: The Case of $\mathrm{CO}_{2}$ Emissions. Modern Economy, 12, 1703-1717.

https://doi.org/10.4236/me.2021.1212086

Received: November 4, 2021

Accepted: November 30, 2021

Published: December 3, 2021

Copyright $\odot 2021$ by author(s) and Scientific Research Publishing Inc. This work is licensed under the Creative Commons Attribution International License (CC BY 4.0).

http://creativecommons.org/licenses/by/4.0/

\section{(c) (i) Open Access}

\begin{abstract}
The general objective of this paper is to analyze the influence of economic growth on $\mathrm{CO}_{2}$ emissions in Republic of the Congo. The data used cover the period 1980-2015 and were extracted from the World Bank's World Development Indicator (WDI 2021) database. Through ARDL modeling, the results show the existence of an inverted U-shaped curve between economic growth and carbon dioxide emissions in Republic of the Congo over the period. However, the Gross Domestic Product variable has no effect on carbon dioxide emissions in the short term. With respect to the environmental protection policy instruments deployed, Republic of the Congo represents a good example of governance. Thus, we recommend that the government strengthen environmental protection and renewable energy policies so that economic growth is always achieved without carbon dioxide emissions exceeding environmentally acceptable limits.
\end{abstract}

\section{Keywords}

Economic Growth, Environment, Pollution, ARDL, Congo

\section{Introduction}

Economic growth is considered one of the priority objectives of economic policies because of its ability to address poverty, inequality, and income disparities. However, Kpemoua (2016) points out that the development of economic growthgenerating activities is the cause of atmospheric warming, due to the release of carbon dioxide $\left(\mathrm{CO}_{2}\right)$ and pollutants.

In the economic literature, the relationship between economic growth and the 
natural environment gives rise to a number of works whose reading reveals cleavages on the theoretical and empirical levels. On the theoretical level, the relationship pits two currents of environmental economics against each other: the weak and strong approaches to sustainability. The work of Hartwick (1977) argues that an integrated approach to growth must necessarily take into account the notion of externality, which was neglected by Adam Smith.

On the empirical level, thinking has focused more on the idea of the existence of a Kuznets environmental curve (Kuznets, 1955), which relates the level of per capita income to the quality of the environment. According to this curve, quality will increase with income, but up to a certain point beyond which it will decrease. This concerns all continents and no country is exempt. Several studies prove the existence of an inverted U-shaped curve (Berahab, 2017).

The study of the effects of economic growth on environmental degradation in Republic of the Congo is crucial. Indeed, this country is part of the Congo Basin, including, among others, the Democratic Republic of the Congo, Cameroon, Gabon and Equatorial Guinea. This basin of 3.68 million $\mathrm{km}^{2}$ constitutes a mosaic of forests, savannahs, swamps, rivers, flooded forests and peat bogs. The stakes are enormous, not only for the countries of the region but also for the planet in terms of ecological benefits.

This paper is an empirical contribution to economics in that it departs from much of the work that argues for the devastating environmental effects of the activities of oil and timber-producing countries. This finding can be qualified if countries use environmental protection policies and programs.

To date, only one study exists on the environmental effects of economic growth in Republic of the Congo. It is therefore difficult to know whether growth and income-generating activities are carried out in accordance with the national environmental protection policy and whether the latter is effective. For a developing country such as Congo, there is an environmental risk in seeking to increase and exploit oil deposits and forest areas without reference to environmental standards and criteria. For this reason, in-depth studies are also needed to take into account the usefulness of determining the turning point and the limits that must not be crossed in order for activities to be consistent with the ecological footprint. However, it is difficult to establish in this article alone, the completeness of carbon dioxide emitting activities as well as their proportion in the GDP formation process in Republic of the Congo.

The relationship between economic growth and the environment in Republic of the Congo is particularly indexed because of the oil industry. Indeed, oil exploitation contributes to more than $80 \%$ of the national budget and public expenditures. The extraction of oil results in colossal emissions to the environment. In addition, there is the production of wood through deforestation. Emissions from agricultural activities and transportation are not negligible. In total, $\mathrm{CO}_{2}$ emissions in Congo amount to $1292.10 \mathrm{Gg}$.

Figure 1 and Figure 2 below illustrate the evolution of carbon dioxide emissions and economic growth. 


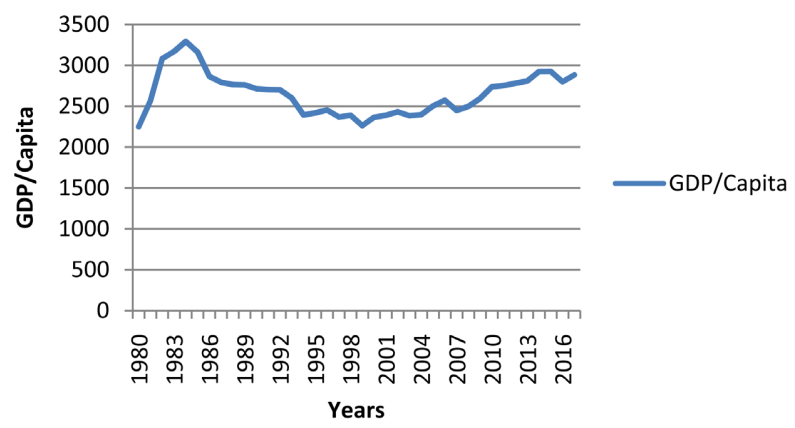

Figure 1. Evolution of economic growth between 1980 and 2015. Source: Author, based on WDI data.

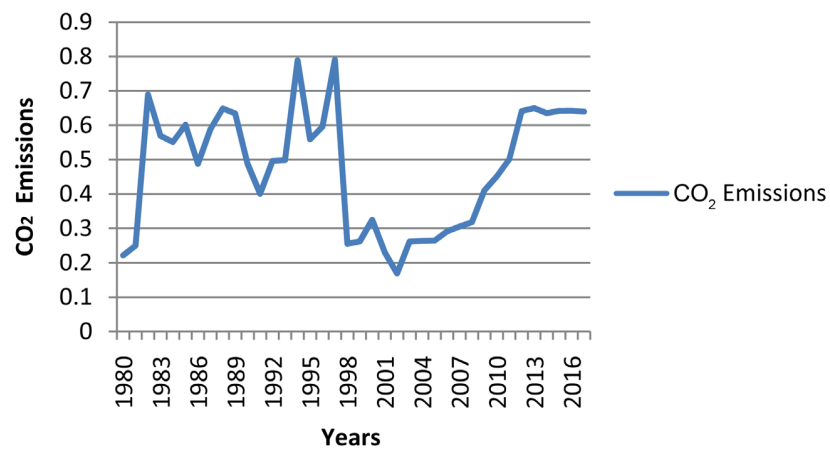

Figure 2. Evolution of carbon dioxide emissions 1980-2015. Source: Author, based on WDI data.

The representative curve of the GDPH shows an increasing trend between 1980 and 1984. From 1985, it began to fall, reaching a low level in 1999. From 2000 to 2017, this curve had an upward trend.

The increase during the first phase is the result of the implementation of activities under the Congo's development plans and programs, particularly the three-year program and the five-year plan for 1982-1986. On the other hand, the decline between 1980 and1985 is explained by socio-political unrest from 1992 onwards. The increase in growth from 2000 to 2017 is the corollary of oil activities (boom between 2008 and 2011) with an average economic growth of 7\% per year.

$\mathrm{CO}_{2}$ emissions increased between 1980 and 1983. Then, the trend progressively decreased until it reached its lowest level in 2002; well before resuming its initial increasing pace, notably between 2003 and 2017.

Taking into account the first graph, we can see that the two phases of growth in $\mathrm{CO}_{2}$ emissions correspond to periods when economic growth in Congo shows an upward trend. In other words, the increase in economic growth in Congo translates into an increase in $\mathrm{CO}_{2}$ emissions.

However, there are instruments in place in the Congo to manage and protect the environment. These include Law No. 003/91 of April 24, 1991 on environmental protection, the National Land Use Plan, and the policy for the preservation of the environment and ecosystems. In addition, the Congo has been pro- 
moting the international initiative known as the "Extractive Industries Transparency Initiative-EITI" and the REDD+ process since 2008.

Despite these achievements, Republic of the Congo has experienced a warming of about $0.6^{\circ} \mathrm{C}$ in recent years. The scenarios established for climate change in the Congo all reveal the existence of warming with acceleration in 2030, and a spatio-temporal evolution of precipitation.

It is becoming increasingly necessary for researchers to address the issue of the impact of economic growth on the quality of the environment in Congo. The current increase in $\mathrm{CO}_{2}$ emissions can be attributed to the high growth rates that this country has experienced in recent years. In light of these findings, we ask ourselves whether there is an environmental Kuznets curve in Congo. In other words, is there a bell-shaped curve between economic growth and $\mathrm{CO}_{2}$ emissions in Congo?

The main objective of this work is to analyze the effect of economic growth on $\mathrm{CO}_{2}$ emissions in Congo. We support, like Jalil and Mahmud (2009), Shahbaz et al. (2013), the hypothesis that there is a bell-shaped curve between economic growth and $\mathrm{CO}_{2}$ emissions in Congo.

After the Introduction (I), this paper presents in the following the Literature Review (II), the Methodology (III), the Results (VI), and the Conclusion and Policy Recommendations (V).

\section{Review of the Literature}

The role of the environment in economic growth has been the subject of several studies. The medium-term depletion of natural resources, due to economic and environmental trends since the Industrial Revolution, has been highlighted. This could slow down economic growth in the long term. In this line of research, Georgescu-Rogen (1979) notes that the race towards economic growth has resulted in the use of resources beyond the limits of the current biosphere. At this rate, there will be an impoverishment of the natural heritage of future generations.

Two sustainability options are put forward: strong sustainability and weak sustainability.

Weak sustainability requires that natural capital be taken into account in growth models so that the capital available to society does not decrease over time. For strong sustainability, it is the economic activity that is integrated into the biosphere and not the other way around. From this point of view, it is not possible for natural capital to decrease over time to allow future generations to have a level of natural resources as high as today's.

In this study, we rely on the weak sustainability approach because it refers to the notion of sustainable development. The research on the relationship between economic growth and the environment will focus on the determination of an environmental Kuznets curve or inverted $U$ curve, signifying the relationship between the inequalities between a country's environmental indicators and economic development. 
The pioneering work of Grossman and Krueger (1991, 1995) demonstrated the existence of an inverted- $U$ curve for most of the environmental indicators selected in their study in general and the air quality indicator in particular. These authors used a random effects model and a sample consisting of several different countries. In the sense, Chiu (2012), applying the new threshold effects estimation method with smooth panel transition (PSTR) to a sample of 52 developing countries over the period 1972 to 2003 , shows that there is a robust threshold effect between deforestation and real income, and that the evidence of the Kuznets hypothesis in the case of deforestation is apparent. In other words, when real income increases, deforestation also increases, but when income reaches a certain level, deforestation decreases.

On their part, Farhani et al. (2014), by studying two different specifications of CEK for 10 Middle East and North Africa (MENA) countries over the period 1990-2010 using panel data methods; successively showed that for the first specification, namely CEK, there is an inverted U-shaped relationship between environmental degradation and income and that for the second specification, namely modified CEK (MCEK), there is also an inverted U-shaped relationship between sustainability and human development.

Besides these two studies, we point to the one conducted by Iwata et al. (2011), whose objective was to test whether the Kuznets environmental curve (CEK) hypothesis for $\mathrm{CO}_{2}$ emissions is satisfied using panel data from 28 countries and taking nuclear power into account. Thus, based on an error correction model and the mean group estimation (MGE) method, the main results found by these authors indicate the following: 1) the impacts of nuclear power on $\mathrm{CO}_{2}$ emissions are significantly negative, 2) $\mathrm{CO}_{2}$ emissions increase monotonically in all cases: OECD and non-OECD countries, and 3) the growth rate of $\mathrm{CO}_{2}$ emissions with income decreases in OECD countries and increases in non-OECD countries.

More recently, Apergis and Ozturk (2015), pursuing the objective of testing the Kuznets environmental curve hypothesis for 14 countries covering the period 1990-2011, reached after estimating a dynamic panel model by the generalized method of moment (in the multivariate framework comprising: $\mathrm{CO}_{2}$ emissions, GDP per capita, population density, land, industry shares in GDP, and four indicators that measure institutional quality) to the result that, there is an inverted U-shaped association between emissions and income per capita. Moreover, their variables of interest have the expected signs and are statistically significant, providing empirical support for the presence of an environmental Kuznets curve hypothesis.

On the other hand, Shahbaz et al. (2013), by empirically investigating the relationship between $\mathrm{CO}_{2}$ emissions, energy intensity, economic growth and globalization using annual data over the period 1970-2010 (for the Turkish economy) and a VECM model, showed that energy intensity and economic growth (globalization) increase $\mathrm{CO}_{2}$ emissions. This validates the presence of an inverted U-shaped curve between these quantities. 
For Berahab (2017), there is also a long-term inverted- $U$ curve between economic growth and carbon dioxide emissions in Morocco. Indeed, in his study aimed at examining how economic growth impacts the environment, he obtains results through the $\mathrm{ARDL}$ technique that validate the CEK hypothesis; in that they reveal the following: In a first phase, economic growth leads to a higher level of $\mathrm{CO}_{2}$ emissions, however, reaching a given threshold (inflection point), these emissions decrease.

The literature review shows that the divide between strong and weak sustainability is not dissipated. The relationship between economic growth and $\mathrm{CO}_{2}$ emissions is more studied with panel data than with time series. On this, the new method of threshold effect estimation with smooth panel transition (PSTR) is increasingly applied. For time series, it is more the ARDL process. The studies are essentially aimed at determining the existence of an environmental Kuznets curve.

Studies for Republic of the Congo are rare. In addition, other studies on the Congo Basin in general do not establish a nomenclature or a classification of activities according to their degree of $\mathrm{CO}_{2}$ emission. While recognizing that such an objective requires the mobilization of several means, our study clearly points to the oil and timber sectors as the main sources of $\mathrm{CO}_{2}$ emissions for the Congo. Hence, the interest of a warning to the political authorities on environmental governance is necessary.

\section{Methodology}

In this article, we rely on the ARDL process, although it is not widely used (Jalil \& Mahmud, 2009; Nasir \& Rehman, 2011; Robalino-López et al., 2015). Dinda (2004) correctly points out that most empirical studies test the Kuznets environmental curve hypothesis use panel data embedded in a reduced-form, quadratic or cubic model.

However, both approaches rely on the following theoretical model:

$$
y_{i t}=\alpha_{i t}+\beta_{1} x_{i t}+\beta_{2} x_{i t}^{2}+\beta_{3} x_{i t}^{3}+\beta_{4} z_{i t}
$$

With $y$ the environmental variable, $x$ the per capita income, $z$ the set of other variables that can influence environmental degradation, $\alpha$ is a constant and $\beta_{k}$ the coefficients of the $k$ explanatory variables. The subscripts $i$ and $t$ denote the country and time, respectively.

We use the following temporal analytical framework (2) to empirically test the hypothesis of an inverted $\mathrm{U}$-shaped curve in Congo. Hence, the indices $\mathrm{i}$ and $\mathrm{t}$ designating respectively the country and the time are excluded in order to take into account only our individual, namely Congo.

Therefore, Equation (1) becomes:

$$
y_{t}=\alpha_{t}+\beta_{1} x_{t}+\beta_{2} x_{t}^{2}+\beta_{3} Z_{t}
$$

The relationship between economic growth and $\mathrm{CO}_{2}$ emissions can be schematized as follows (Figure 3). 


$$
\boldsymbol{\beta}_{1}>0, \boldsymbol{\beta}_{2}=0
$$

Relation linéaire positive

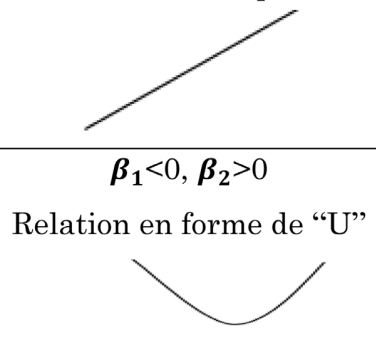

$$
\boldsymbol{\beta}_{1}<0, \boldsymbol{\beta}_{2}=0
$$

Relation linéaire négative

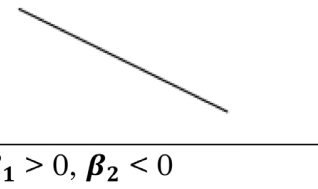

Relation en forme de « $U$ » inversé

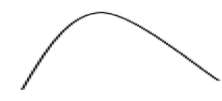

Figure 3. Different forms of the relationship between growth and $\mathrm{CO}_{2}$ emissions. Source: Author, according to the literature.

These are the four different forms of the relationship between growth and $\mathrm{CO}_{2}$ emissions, depending on the values that the coefficients $\beta_{1}$ and $\beta_{2}$ can take.

The empirical model derived from Equation (2) can be written as follows:

$$
\mathrm{E}-\mathrm{CO}_{2}=a_{0}+a_{1} \text { GDP-hab }+a_{2} \text { GDP-hab } 2+a_{3} \mathrm{OC}+a_{4} \mathrm{VA}-\mathrm{AGRI}+\varepsilon_{t}
$$

$\mathrm{E}-\mathrm{CO}_{2}$ is carbon dioxide emissions;

GDP-hab is the gross domestic product per capita (indicator of economic growth). In the long run, its increase is accompanied by an increase in $\mathrm{CO}_{2}$ emissions.

GDP-hab2 is the square of GDP-hab, its introduction in the model allows to take into account the possibility of an "inverted U relationship" between economic growth and $\mathrm{CO}_{2}$ emissions. Its sign should be negative.

$\mathrm{OC}$ denotes the degree of openness that causes an increase in $\mathrm{CO}_{2}$ emissions. Strong environmental regulations generally result in the relocation of polluting industries to countries with weak environmental regulations.

VA-AGRI: the added value of the agricultural sector allows capturing the effects of agricultural activities on $\mathrm{CO}_{2}$ emissions. Agriculture modifies natural ecosystems, with a positive relationship between the value added of the agricultural sector and $\mathrm{CO}_{2}$ emissions.

$\varepsilon_{t}$ the set of perturbations;

$a_{0}$ the model constant and $a_{1}, a_{2}, a_{3}$ aini and $a_{4}$ the coefficients associated with our variables of interest and control.

All these variables were chosen according to the empirical literature, as well as the availability of certain information at the level of the base that was exploited. They are taken from the World Bank's World Development Indicator (WDI) database, for the period from 1980 to 2017, and cover the Congo. Moreover, this period was chosen because it allows us to assess the interaction between our explained variable and the variables of interest over a long period. Finally, since these data are macro in nature, there is no need to extrapolate the results. These results already concern the population as a whole. This is different from an analysis that relies on micro data, based on a survey of a sample of the population. 


\section{Results and Interpretations}

The results of the descriptive statistics (Table 1), correlation (Table 2) and Unit root tests (Table 3 ) are presented in the appendix.

The descriptive statistics over the study period show that the average value of GDP per capita is 2654.770 (million FCFA). Moreover, these values fluctuated in the range of 2248.057 (million FCFA) to 3292.427 (million FCFA). With a standard deviation of 263.7967 FCFA, the GDPhab values are scattered around the mean. $50 \%$ of the values are above $2650.281 \mathrm{FCFA}$, the remaining $50 \%$ are below.

Trade openness (TO) fluctuates between 0.571407 and 1.656459 , the $\mathrm{E}-\mathrm{CO}_{2}$ variable has a mean of 0.47 and there is a concentration of its dispersion due to the standard deviation of 0.176417 .

A positive correlation is established between the variables E- $\mathrm{CO}_{2}$ and GDP-hab. Indeed, the value of the correlation coefficient (0.55) between these two variables is positive and significant at the one percent threshold. This indicates that the evolution of $\mathrm{CO}_{2}$ emissions in Congo could be linked to $55.18 \%$ to that of GDP-capita. In the same sense, we note the existence of a positive correlation between $\mathrm{CO}_{2}$ emissions and the GDP-hab2 variable. Given that the correlation coefficients between E- $\mathrm{CO}_{2}$ and GDP-hab and $\mathrm{ECO}_{2}$ and GDP-hab2 have the same signs (positive), this implies that there is no presumption of a bell curve between $\mathrm{CO}_{2}$ emissions and economic growth in Congo. Finally, the same table shows us that there does not seem to be a statistical link between the variables E- $\mathrm{CO}_{2}$ and OC on the one hand and VA-AGRI and $\mathrm{CO}_{2}$ on the other, since the correlation coefficients for each of these two pairs of variables $(-0.131536$ and $0.252708)$ are not significant at any threshold (1\%,5\% and 10\%).

The stationarity tests carried out (Augmented Dickey Fuller, Phillips Perron and Kwiatkowski-Phillips-Schmidt) reveal some stationary variables in level (E-CO ${ }_{2}$ and VA-AGRI) and others in first difference (GDPhab, GDPhab2 and $\mathrm{OC})$. On the other hand, no variable is stationary in second difference, which is necessary and sufficient to apply the ARDL procedure.

The ARDL procedure allows to solve the problems of variables not integrated at the same order. Moreover, this procedure has good properties for small samples compared to other techniques. It corrects the problem of serial correlation and endogeneity, by appropriately increasing the order of the explanatory variables.

In practice, the approach consists, in the first step, in searching for the existence of a long term relationship by means of the calculation of F-statistics in order to test the significance of the shifted levels of the variables in the form of error correction. The second step is to determine the orders of the lags in the ARDL model using the Schwartz Information Criterion (SIC). The last step is to estimate the selected model by the ordinary least squares method in order to obtain a long-run estimate of the coefficients of the cointegration relation.

The main results are as follows (Figure 4).

The ARDL $(1,1,2,2)$ model is the one that suffers less information loss. The coefficient of determination of the ARDL $(1,1,2,2)$ model in our study is 0.685 , 
Table 1. Descriptive statistics.

\begin{tabular}{cccccc}
\hline & E_CO & PIB_HAB & PIB_HAB2 & OC & VA_AGRI \\
\hline Mean & 0.474211 & 2654.770 & 7115562. & 1.218372 & 7.862271 \\
Median & 0.497525 & 2650.281 & 7026419. & 1.310504 & 7.515010 \\
Maximum & 0.790966 & 3292.427 & 10840076 & 1.656459 & 13.86707 \\
Minimum & 0.168972 & 2248.057 & 5053760. & 0.571407 & 3.383113 \\
Std. Dev. & 0.176417 & 263.7967 & 1439423. & 0.270554 & 3.133955 \\
Jarque-Bera & 2.491631 & 2.067964 & 3.327669 & 4.789437 & 2.713924 \\
Probabilité & 0.287706 & 0.355588 & 0.189411 & 0.091198 & 0.257442 \\
Observations & 38 & 38 & 38 & 38 & 38 \\
\hline
\end{tabular}

Source: Author, from Eviews9.

Table 2. Matrix of correlation coefficientsion.

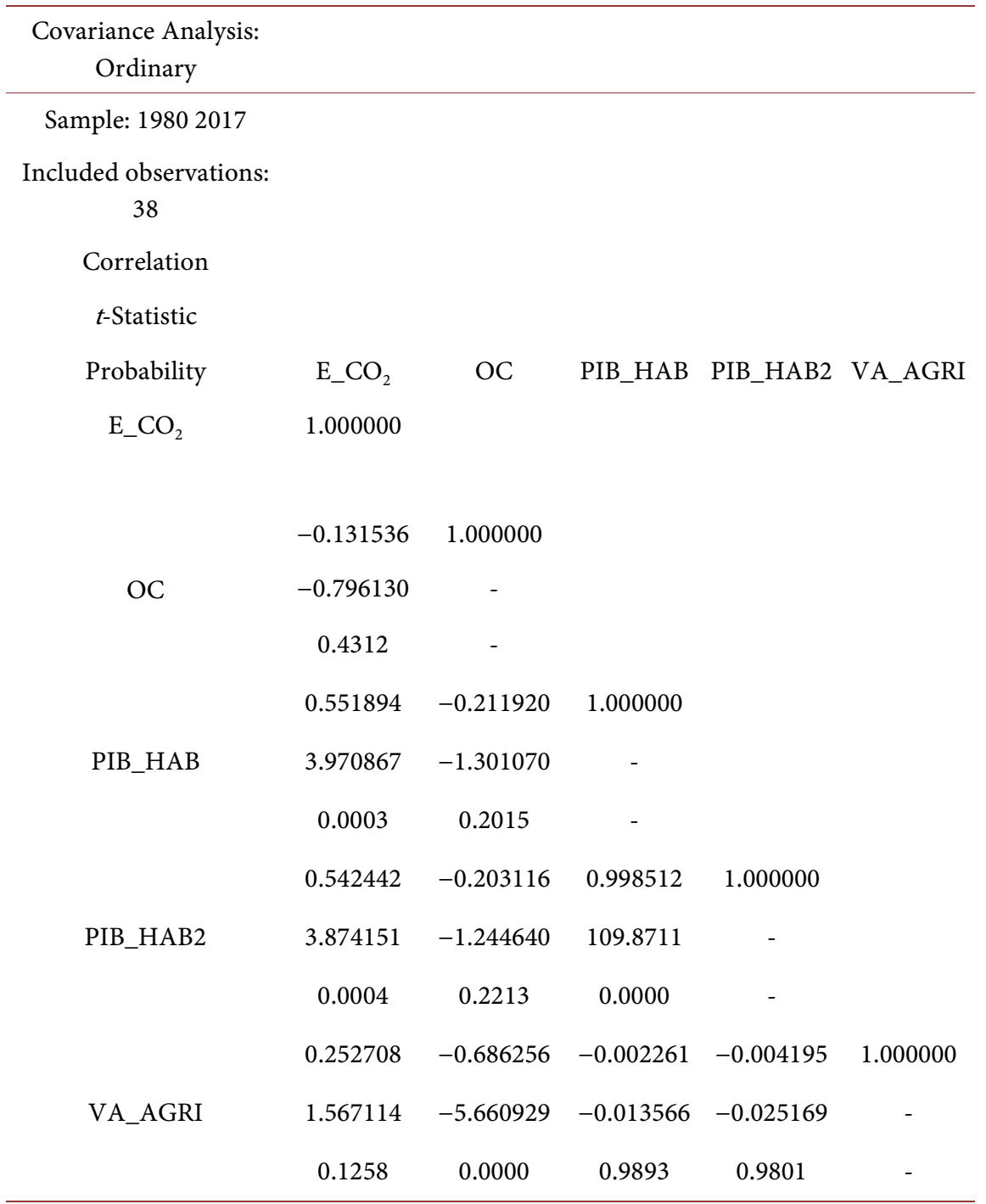

Source: Author, from Eviews9. 


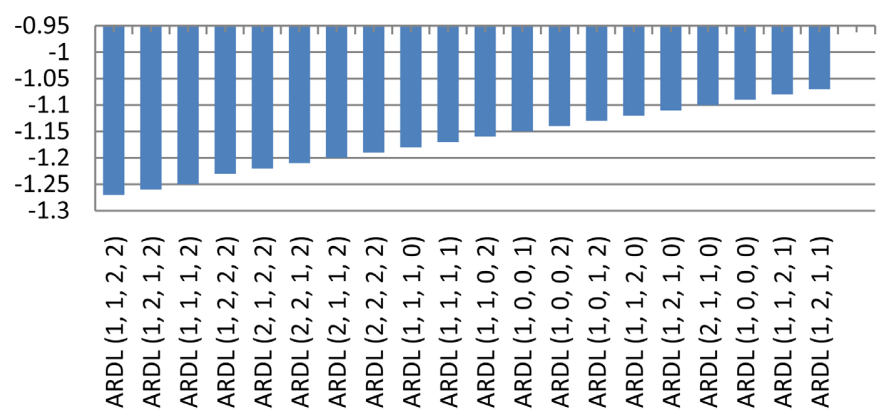

Figure 4. Top twenty of the best models. Source: Author, from Eviews9.

Table 3. Unit root tests.

\begin{tabular}{|c|c|c|c|c|c|c|c|}
\hline Variables & $\begin{array}{l}\text { Type } \\
\text { of test }\end{array}$ & $\begin{array}{c}\text { No } \\
\text { constant } \\
\text { and no } \\
\text { trend }\end{array}$ & $\begin{array}{l}\text { With } \\
\text { constant } \\
\text { and no } \\
\text { trend }\end{array}$ & $\begin{array}{l}\text { With } \\
\text { constant } \\
\text { and } \\
\text { trend }\end{array}$ & $t$-statistic & Probabilities & Decisions \\
\hline \multirow{3}{*}{$\mathrm{E}-\mathrm{CO}_{2}$} & $\mathrm{ADF}$ & Yes & Yes & Yes & -7.58 & 0.00 & $\mathrm{I}(\mathrm{I})$ \\
\hline & $\mathrm{PP}$ & No & No & No & -3.09 & 0.041 & $\mathrm{I}(0)$ \\
\hline & KPSS & - & & Yes & Yes & 0.12 & - \\
\hline \multirow{3}{*}{ GDP-hab } & $\mathrm{ADF}$ & Yes & Yes & Yes & -4.09 & 0.014 & I (I) \\
\hline & $\mathrm{PP}$ & Yes & Yes & Yes & -4.74 & 0.09 & $\mathrm{I}(\mathrm{I})$ \\
\hline & KPSS & - & & Yes & Yes & 0.12 & - \\
\hline \multirow{3}{*}{ GDP-hab2 } & $\mathrm{ADF}$ & Yes & Yes & Yes & -3.09 & 0.002 & $\mathrm{I}(\mathrm{I})$ \\
\hline & $\mathrm{PP}$ & Yes & Yes & No & -3.94 & 0.004 & $\mathrm{I}(\mathrm{I})$ \\
\hline & KPSS & - & & Yes & Yes & 0.11 & - \\
\hline \multirow{3}{*}{$\mathrm{OC}$} & $\mathrm{ADF}$ & Yes & Yes & Yes & -6.56 & 0.00 & $\mathrm{I}(\mathrm{I})$ \\
\hline & $\mathrm{PP}$ & Yes & Yes & Yes & -6.44 & 0.00 & I (I) \\
\hline & KPSS & - & & Yes & Yes & 0.084 & - \\
\hline \multirow{3}{*}{ VA-AGR } & $\mathrm{ADF}$ & Yes & Yes & Yes & -4.19 & 0.012 & $\mathrm{I}(\mathrm{I})$ \\
\hline & $\mathrm{PP}$ & Yes & Yes & Yes & -6.02 & 0.00 & I (I) \\
\hline & KPSS & - & & No & Yes & 0.10 & - \\
\hline
\end{tabular}

Source: Author, from Eviews9. Notes. These are the Augmented Dickey Fuller (ADF), Phillips Perron (PP) and kwiatkowski-Phillips-Schmidt (KPSS) stationarity tests.

i.e. $69 \%$, which implies that the fluctuations in $\mathrm{CO}_{2}$ emissions in Republic of the Congo can be explained by the previously chosen variables (GDP-bab, GDP-hab2, VA-AGRI, OC) up to $69 \%$.

The results in the appendix show that the series studied do not present an autocorrelation problem in the residuals. The probability associated with the Lagrange Multiplier Test $($ Table 4$)$ is greater than 0.005 , i.e. Prob. F $(2,23)=$ 0.5788 . The model is well specified and robust following the autocorrelation result and the Ramsey Test (Table 5). The Cusum Test (Figure 5) allows us to 


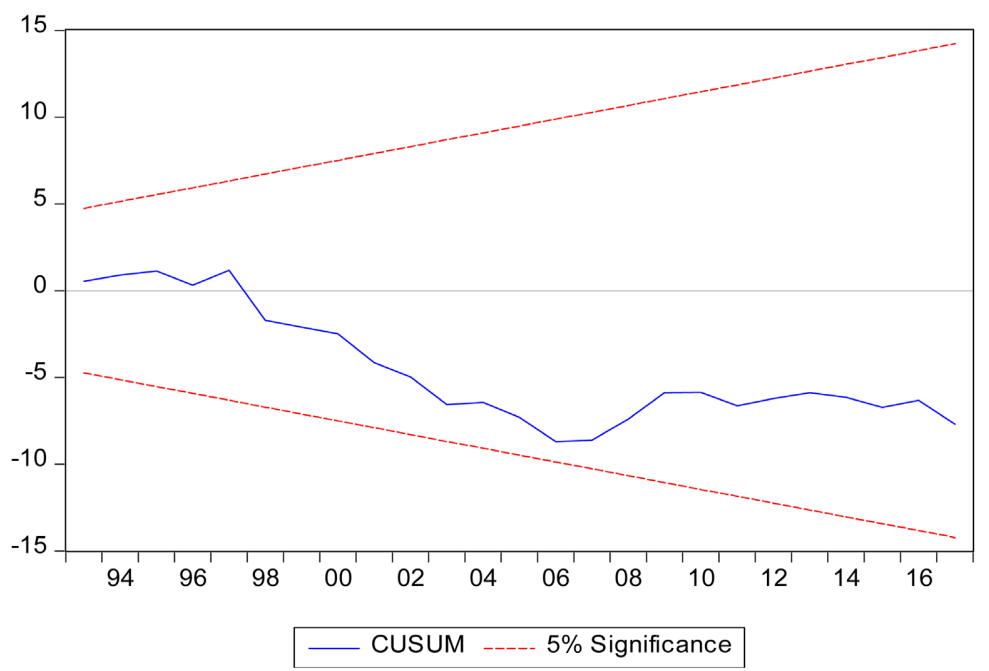

Figure 5. Model stability corridor. Source: Author, from Eviews9.

Table 4. Lagrange multiplier test for autocorrelation.

\begin{tabular}{cccc}
\hline F-statistic & 0.559981 & Prob. F $(2,23)$ & 0.5788 \\
Obs ${ }^{\star}$ R-squared & 1.671588 & Prob. Chi-Square (2) & 0.4335 \\
\hline
\end{tabular}

Source: Author, from Eviews9.

Table 5. Ramsey test.

\begin{tabular}{rccc}
\hline & Value & Df & Probability \\
\hline$t$-statistic & 1.039088 & 24 & 0.3091 \\
F-statistic & 1.079704 & $(1,24)$ & 0.3091 \\
\hline
\end{tabular}

Source: Author, from Eviews9.

conclude that the model is structurally stable, and therefore can be used for forecasting purposes. Also, the ADL Bounds test (Table 6) shows the existence of a long term relationship between the variables retained in this work. Hence, the model is robust and its estimates are open to interpretation.

Concerning the long-run cointegration test and the short-run results, Table 7 below reveals that the recall force or the lagged residual from the long-run equilibrium Equation (CointEq) is negative and significant at the $1 \%$ level. This confirms the existence of an error correction mechanism; and thus the fact that the E- $\mathrm{CO}_{2}$ variable will be recalled towards the long term target with an estimated degree of -0.76 .

With regard to the short-term results themselves, it emerges that carbon dioxide emissions in Republic of the Congo depend negatively on the past values of value added in the agricultural sector and that trade openness has a positive influence on these emissions. On the other hand, the variables GDP-hab and GDP-hab2 do not seem to have an effect on carbon dioxide emissions in the short term.

The long-term results are presented in Table 8 below. 
Table 6. Results of the ARDL bounds test.

\begin{tabular}{ccc}
\hline Test Statistic & Value & $\mathrm{K}$ \\
\hline F-statistic & 5.610925 & 3 \\
Critical Value Bounds & & \\
Significance & I0 Bound & I1 Bound \\
$10 \%$ & 2.37 & 3.2 \\
$5 \%$ & 2.79 & 3.67 \\
$2.5 \%$ & 3.15 & 4.08 \\
$1 \%$ & 3.65 & 4.66 \\
\hline
\end{tabular}

Source: Author, from Eviews9.

Table 7. Short term results.

\begin{tabular}{|c|c|c|c|c|}
\hline Variables & Coefficients & Standard Erros & $t$-statistic & Probabilities \\
\hline D (PIB-hab) & -0.000752 & 0.002012 & -0.373567 & 0.7119 \\
\hline D (PIB-hab2) & 0.000000 & 0.000000 & 0.425559 & 0.6741 \\
\hline D (PIB-hab2 (-1)) & -0.000000 & 0.000000 & -1.650040 & 0.1114 \\
\hline D (VA-AGRI) & -0.010584 & 0.014386 & -0.735712 & 0.4688 \\
\hline D (VA-AGRI $(-1))$ & $-0.043625^{\star}$ & 0.014971 & -2.914014 & 0.0074 \\
\hline $\mathrm{D}(\mathrm{OC})$ & $0.320065^{\star *}$ & 0.120963 & 2.645977 & 0.0139 \\
\hline Coint Equation $(-1)$ & $-0.762943^{\star}$ & 0.134667 & -5.665393 & 0.0000 \\
\hline \multicolumn{5}{|c|}{$\begin{array}{c}\text { Cointeq }=\text { E- } \mathrm{CO}_{2}-\left(0.0069^{\star} \text { PIB-hab }-0.0000^{\star} \text { PIB-hab2 }+\right. \\
\left.0.0307^{\star} \text { VA-AGRI }+0.4110^{\star} \text { OC }-10.4227\right)\end{array}$} \\
\hline
\end{tabular}

Source: Author, from Eviews9. NB: ${ }^{*},{ }^{* *},{ }^{* *}$ Significant at the $1 \%, 5 \%$ and $10 \%$ levels respectively.

Table 8. Long term results.

\begin{tabular}{ccccc}
\hline Variables & Coefficients & Standard Erros & $t$-statistic & Probabilities \\
\hline PIB-hab & $0.006860^{\star *}$ & 0.002486 & 2.759499 & 0.0107 \\
PIB-hab2 & $-0.048601^{\star *}$ & 0.000 & -2.539161 & 0.0177 \\
VA-AGRI & $0.030744^{\star *}$ & 0.014113 & 2.178336 & 0.0390 \\
OC & $0.410987^{\star *}$ & 0.155713 & 2.639380 & 0.0141 \\
C & $-10.422707^{*}$ & 3.520333 & -2.960716 & 0.0066 \\
\hline
\end{tabular}

Source: Author, from Eviews9. NB: ${ }^{*},{ }^{* *},{ }^{* *}$ Significant at the $1 \%, 5 \%$ and $10 \%$ levels respectively.

The coefficient associated with the GDP per capita variable is positive (as expected) and statistically significant at the $5 \%$ level. This means that per capita production and carbon dioxide emissions are positively correlated in Republic of 
the Congo. In other words, an increase in per capita production leads to an increase in carbon dioxide emissions, all other things being equal, but only to a small extent, since the value of the estimated coefficient $(0.006860)$ is much closer to 0 than 1. Far from being paradoxical, this result reflects the fact that the evolution of Congolese economic growth is not too disrespectful of the environment; contrary to what could be the case for large polluters such as China for example.

Furthermore, these same results reveal that the coefficient of the variable GDP-hab2 is significant and has the expected sign (negative). Therefore, and taking into account the sign of the coefficient of the GDP-hab2 variable (positive), we can conclude, according to Table 7 , that there is indeed an inverted U-shaped curve between economic growth and carbon dioxide emissions in Republic of the Congo, and that our research hypothesis is validated. With respect to our literature review, our results are consistent with the weak sustainability perspective (where economic growth is considered as a stabilizing factor of $\mathrm{CO}_{2}$ emissions over time) on the one hand, and on the other hand, resemble those obtained by Jalil and Mahmud (2009) and Berahab (2017), respectively in China and Morocco. Moreover, the existence of an environmental Kuznets Curve revealed through this study, reflects the fact that in the long run, Republic of the Congo could move from a polluting industrial economy to a less polluting service economy.

We also note that the coefficients of our control variables (OC and VA-AGRI) all have the expected signs and are significant at the 5\% level, which implies the absence of a carry-over effect on the constant of our model.

\section{Conclusion and Policy Recommendation}

In view of the magnitude of the hazards of climate change today, we felt that it would be interesting to complete the literature on Environmental Economics by addressing the topic entitled: "Influence of economic growth on carbon dioxide emissions in Republic of the Congo".

The general objective of our study was to analyze the influence of economic growth on $\mathrm{CO}_{2}$ emissions in Republic of the Congo and specifically to determine the nature of the relationship between $\mathrm{CO}_{2}$ emissions and economic growth in the long run. To achieve this, we used ARDL modeling, which was performed using Eviews9 software and data from the World Bank's WDI database covering a period from 1980 to 2017 .

From the results of this modeling, it appears that the variables GDP-hab and GDP-hab2 do not seem to have an effect on carbon dioxide emissions in the short term and that, like the work done by Jalil and Mahmud (2009) and Berahab (2017), there is really an inverted U curve between economic growth and carbon dioxide emissions in Republic of the Congo, thus validating our research hypothesis.

Beyond this study, we believe that a similar study, but also taking into account the determination of the turning point may be useful to enrich the literature on 
environmental economics in the Congolese context.

Finally, we make the recommendation that governments should strengthen sustainable natural resource management and promote renewable energy to improve the long-term well-being of the population. In addition to this, they can also place special emphasis on improving the state of roads.

\section{Conflicts of Interest}

The authors declare no conflicts of interest regarding the publication of this paper.

\section{References}

Apergis, N., \& Ozturk, I. (2015). Testing Environmental Kuznets Curve Hypothesis in Asian Countries. Ecological Indicators, 52, 16-22. https://doi.org/10.1016/j.ecolind.2014.11.026

Berahab, R. (2017). Emissions de Dioxyde de Carbone et Croissance Economique au Maroc: Une Analyse de la Courbe Environnementale de Kuznets. Policy Center for the New South.

Chiu, Y. B. (2012). Deforestation and the Environmental Kuznets Curve in Developing Countries: A Panel Smooth Transition Regression Approach. Canadian Journal of Agricultural Economics, 60, 177-194. https://doi.org/10.1111/j.1744-7976.2012.01251.x

Dinda, S. (2004). Environmental Kuznets Curve Hypothesis: A Survey. Ecological Economics, 49, 431-455. https://doi.org/10.1016/j.ecolecon.2004.02.011

Farhani, S., Mrizak, S., Chaibi, A., \& Rault, C. (2014). The Environmental Kuznets Curve and Sustainability: A Panel Data Analysis. Energy Policy, 71, 189-198. https://doi.org/10.1016/j.enpol.2014.04.030

Georgescu-Rogen, N. (1979). La décroissance: Entropie-Ecologie-Economie. Éditions Sang de la terre.

Grossman, G., \& Krueger, A. (1991). Environmental Impacts of the North American Free Trade Agreement. NBER Working Paper No. 3914. National Bureau of Economic Research, Inc.

Grossman, G., \& Krueger, A. (1995). Economic Growth and the Environment. The Quarterly Journal of Economics, 110, 353-377. https://doi.org/10.2307/2118443

Hartwick, J. (1977). Intergenerational Equity and Investing Rents from Exhaustible Resources. American Economic Review, 67, 972-974.

Hill, R. J., \& Magnani, E. (2002). An Exploration of the Conceptual and Empirical Basis of the Environmental Kuznets Curve. Australian Economic Papers, 41, 239-254. https://doi.org/10.1111/1467-8454.00162

Iwata, H., Okada, K., \& Samreth, S. (2011). A Note on the Environmental Kuznets Curve for $\mathrm{CO}_{2}$ : A Pooled Mean Group Approach. Applied Energy, 88, 1986-1996. https://doi.org/10.1016/j.apenergy.2010.11.005

Jalil, A., \& Mahmud, S. (2009). Environmental Kuznets Curve for $\mathrm{CO}_{2}$ Emissions: A Cointegration Analysis for China. Energy Policy, 37, 5167-5172. https://doi.org/10.1016/j.enpol.2009.07.044

Kpemoua, K. (2016). Analysis of the Nexus between $\mathrm{CO}_{2}$ Emission, Their Restriction and Economic Growth of Togo. MPRA Paper No. 77624. University Library of Munich

Kuznets, S. (1955). Economic Growth and Income Inequality. American Economic Review, 
$45,1-28$.

Nasir, M., \& Rehman, F. U. (2011). Environmental Kuznets Curve for Carbon Emissions in Pakistan: An Empirical Investigation. Energy Policy, 39, 1857-1864. https://doi.org/10.1016/j.enpol.2011.01.025

Robalino-López, A., Mena-Nieto, Á., García-Ramos, J., \& Golpe, A. (2015). Studying the Relationship between Economic Growth, $\mathrm{CO}_{2}$ Emissions, and the Environmental Kuznets Curve in Venezuela (1980-2025). Renewable and Sustainable Energy Reviews, 41, 602-614. https://doi.org/10.1016/j.rser.2014.08.081

Shahbaz, M. Lean, H., \& Farooq, A. (2013). Natural Gas Consumption and Economic Growth in Pakistan. Renewable and Sustainable Energy Reviews, 18, 87-94.

https://doi.org/10.1016/j.rser.2012.09.029 